\title{
Antibiotic and systemic therapies for pneumonia in human immunodeficiency virus (HIV)-infected and HIV-exposed children
}

\author{
Warunee Punpanich ${ }^{1,2}$, Michelle Groome ${ }^{1}$, Lulu Muhe ${ }^{3}$, Shamim A Qazi ${ }^{3}$, Shabir A Madhi ${ }^{1}$ \\ ${ }^{1}$ Respiratory and Meningeal Pathogens Research Unit and Department of Science and Technology National \\ Research Foundation: Vaccine Preventable Diseases; University of the Witwatersrand, South Africa \\ ${ }^{2}$ Department of Pediatrics, Queen Sirikit National Institute of Child Health, College of Medicine, Rangsit University, \\ Thailand \\ ${ }^{3}$ Departments of Child and Adolescent Health and Development and HIV, World Health Organization, Geneva, \\ Switzerland
}

\begin{abstract}
Introduction: Pneumonia is the leading cause of mortality in both human immunodeficiency virus (HIV)-infected and HIV-exposed children. Administration of appropriate empirical antimicrobial and/or adjunctive systemic therapies may improve clinical outcomes.

Methodology: To identify effective antimicrobial and/or adjunctive systemic therapy for pneumonia in HIV-infected and HIV-exposed, uninfected children, we searched for published and unpublished studies from 11 databases including MedLine, Global Health Database, Biological Abstracts (BIOSIS), the Cochrane Central Register of Controlled Trials, the World Health Organization Library Information System, AIDSLine, and the System for Information on Grey Literature in Europe, along with additional four regional databases including African Index Medicus, Latin America and Caribbean, Eastern Mediterranean, and South-East Asian databases. Data from full articles of selected studies were independently extracted by two reviewers.

Results: No a priori planned randomized controlled trials (RCT) were identified, only subgroup analyses of an RCT comparing oral amoxicillin versus parenteral penicillin for severe pneumonia in children. HIV-infected children had significantly higher treatment failure rates compared to their uninfected counterparts. An RCT study investigating adjunctive corticosteroid therapy for Pneumocystis jiroveci pneumonia (PCP) failed to identify a statistically significant reduction in mortality in the treatment group with a relative risk of 0.57 (95\% CI $0.30-1.07)$. A before-after observational study showed substantial beneficial effect of corticosteroid treatment in reducing mortality among HIV-infected children with PCP.

Conclusions: Insufficient evidence exists to identify effective antimicrobial treatment regimens for HIV-associated pneumonia in paediatric populations or confirm the beneficial effect of corticosteroid treatment for HIV-infected children with PCP.
\end{abstract}

Key words: HIV; pneumonia; children; opportunistic infection; meta-analysis; antimicrobial therapy; adjunctive therapy

J Infect Dev Ctries 2012; 6(2):109-119.

(Received 30 March 2011 - Accepted 04 July 2011)

Copyright $(0) 2012$ Punpanich et al. This is an open-access article distributed under the Creative Commons Attribution License, which permits unrestricted use, distribution, and reproduction in any medium, provided the original work is properly cited.

\section{Introduction}

Acute respiratory infections (ARIs), predominantly pneumonia, account for an estimated two million deaths in children under five years of age annually [1], predominantly in industrialising countries [2]. The human immunodeficiency virus (HIV) epidemic has worsened the situation, especially in subSaharan African countries, where HIV contributes to significant childhood mortality including $40 \%$ of all childhood deaths in South Africa, with pneumonia being a leading cause of death in these children [3]. Ninety percent of HIV-infected children live in lowincome African countries with limited access to antiretroviral therapy [4].
In most developing countries, Hemophilus influenzae type b and Streptococcus pneumoniae remain important pathogens in children under five years as protection through conjugate vaccines targeting these pathogens have only recently been scaled up for $H$. infuenzae type $b$ and are yet to be rolled out in developing countries for pneumococcal conjugate vaccine $[5,6]$. Other bacteria identified in the aetiology of community-acquired pneumonia (CAP) include Staphylococcus aureus, non-typhoidal Salmonella, and other gram-negative organisms $[7,8]$. Differences in the aetiology and antibiotic susceptibility patterns of pathogens causing CAP in HIV-affected children may affect the effectiveness of the current World Health 
Organization (WHO) recommendations for the empirical treatment of CAP in HIV-infected children.

Pneumocystis jirovecii is a significant cause of pneumonia (PCP) in HIV-infected children, especially in the absence of antiretroviral (ARV) therapy or prophylactic treatment (CPT), with high (28-63\%) mortality rates [9-15]. The estimated risk of PCP among perinatally HIV-infected children during the first year of life ranges from $7 \%$ to $20 \%$ [16-19]. Younger age $(<1$ year) is associated with increased risk of PCP, especially during the first six months of life [10,15-18,20-24]. Studies from Africa reported PCP prevalence rates from $10 \%$ to $48.5 \%$ among $\mathrm{HIV}$-infected children hospitalized with severe pneumonia $[10-12,14,15]$. Postmortem studies have shown that the prevalence of PCP among HIV-related deaths in children ranged from $11.5 \%$ to $52 \%$ [18,25-29].

The HIV epidemic has changed the epidemiology of pneumonia. The current WHO standard case management antibiotic guidelines for pneumonia treatment may not be as effective in countries with a high burden of HIV infection as it is primarily designed on the premise that $S$. pneumoniae and $H$. influenzae are the leading causes of CAP [30]. Evidence-based guidelines are needed to decrease CAP-related morbidity and mortality in children exposed to and infected with HIV. Currently, there is no standardized approach to antibiotic and/or adjunctive therapy for the management of CAP in countries with a high prevalence of paediatric HIV infection. The objective of this systematic review of various antimicrobial and/or adjunctive systemic treatment strategies is specifically targeted toward determining the most appropriate empirical management of CAP in HIV-infected and HIVexposed, uninfected children.

\section{Methodology}

\section{Search strategies}

The literature search included articles (both published and unpublished) that contained information on HIV-affected children and management of CAP without language restriction. The search was limited to children ( $0-15$ years) and articles published between 1990 to February 2009. We conducted key word searches of eleven databases: MedLine, Global Health Database, Biological Abstracts (BIOSIS), Cochrane Central Register of Controlled Trials (CENTRAL), World Health Organization Library Information System (WHOLIS), AIDSLine, and the System for Information on Grey Literature in Europe (SIGLE), along with four regional databases including African
Index Medicus (AFI), Latin America and Caribbean (LILACS), Eastern Mediterranean, and South-East Asian Databases. The search terms were based on the following key words: pneumonia, HIV infection, HIVexposed, AIDS, treatment, and children. Key words and search strategies were modified and tailored to capture the most sensitive results for each database. For example, three different search strategies were used for the MEDLINE database including MeSH terms, Clinical Query (with sensitive search option), and simple search options using the key words pneumonia, HIV, and child. In contrast, for certain databases where MeSH search option and Clinical Query were not available, advanced or simple search option using Boolean operators were applied. The results were then imported into a bibliographic database from which duplicates were discarded. One reviewer also searched the bibliographic references of review articles for published and unpublished data on pneumonia, treatment and/or management in HIVinfected and HIV-exposed children. We also searched for any ongoing trials conducted in the United States (ClinicalTrials.gov). The date of the most recent searches conducted is February 2009.

\section{Selection criteria}

Types of studies: Initially, we aimed to include only randomized controlled trials (RCTs) comparing different antibiotic regimens, duration of treatment and/or adjunctive systemic therapy for CAP on mortality rates and treatment failure rates in HIVinfected and HIV-exposed children, irrespective of publication status and language. However, observational studies with a control or comparison group were also included because of the limited availability of the RCT studies. Exclusion criteria included ecological studies; studies with less than 20 pneumonia cases; studies investigating prophylaxis against pneumonia (such as vaccines, CPT, micronutrients, and antiretroviral therapy); studies assessing adverse drug reaction; pharmacokinetics studies of antimicrobial agents; and policy papers or review articles.

Study populations were HIV-infected or HIVexposed uninfected children 0 to 15 years of age with CAP. Primary outcome included pneumonia-related mortality (48 hours, 14 days). Secondary outcomes included treatment failure at 48 hours and 14 days post-initiation of treatment. 
Table 1. Characteristics of a study examining the effectiveness of antimicrobial treatment: Jeena PM 2006 [30]

\begin{tabular}{|l|l|}
\hline Methodology & $\begin{array}{l}\text { A sub-analysis of an RCT of 3- to59-month-old children with severe pneumonia (WHO criteria) focusing on the } \\
\text { effectiveness of oral amoxicillin versus parenteral penicillin among HIV-infected children }\end{array}$ \\
\hline Participants & $\begin{array}{l}\text { 106 HIV-infected children with severe pneumonia receiving the assigned treatment regimen were compared with those } \\
\text { who were HIV-uninfected. }\end{array}$ \\
\hline Interventions & Oral amoxicillin and injectable penicillin \\
\hline Outcomes & The primary study endpoint: treatment failure rate by day 2 and day 14 of treatment. \\
\hline Notes & $\begin{array}{l}\text { All HIV-infected children included were either asymptomatic or mildly symptomatic and did not receive antiretroviral } \\
\text { therapy. Both treatment options appeared to be equally inadequate and their response rates were comparable regardless of } \\
\text { HIV status [35]. However, effect of HIV infection was only apparent among young infants }(<1 \text { year) whose treatment } \\
\text { failure rate was approximately three times higher than that of uninfected infants. }\end{array}$ \\
\hline
\end{tabular}

Table 2. Characteristics of a study's risk of bias: Jeena PM 2006 [30]

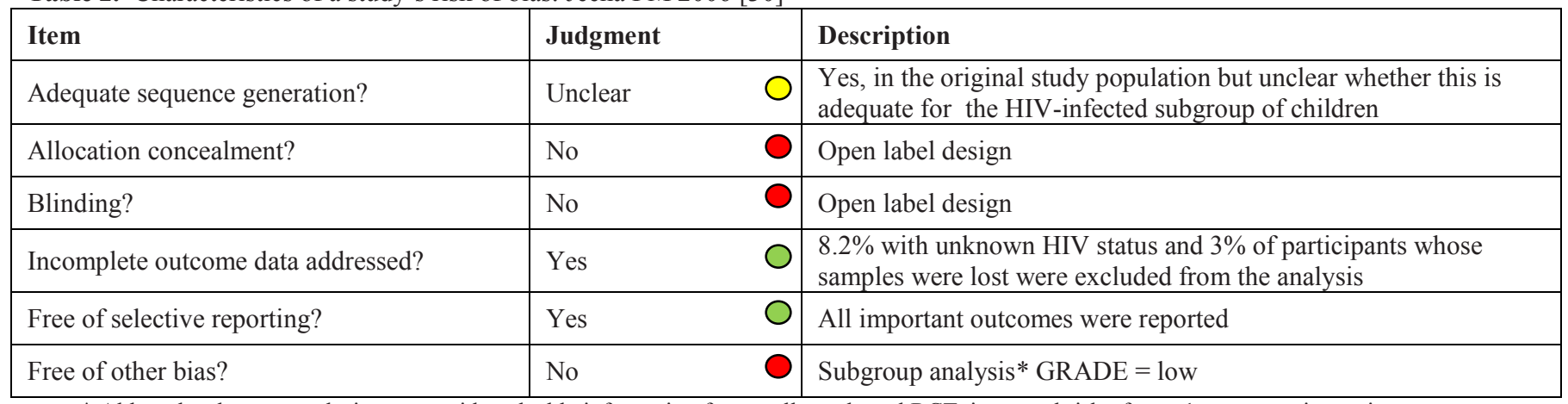

* Although subgroup analysis can provide valuable information from well-conducted RCT, increased risk of type 1 error remains an important concern when interpreting its results $[45,46]$. Further, the finding should be viewed primarily as exploratory [46]. A simulation study shows that the chance of obtaining false positive and thus spurious results is high and the extent is generally underestimated when subgroup analysis is utilized [47].

\section{Data extraction and management}

The abstracts of all articles identified by the searches detailed earlier were independently reviewed by two reviewers using the selection criteria above. Translation of abstracts and articles were obtained for those published in languages other than English. Studies identified as eligible by both reviewers were included in the review. Discordance between reviewers regarding the relevance of a particular study was referred to a third reviewer for final arbitration.

Each reviewer independently extracted the data from included studies. A data extraction form was designed to capture all relevant data from selected studies. This included data on the study design, demographics, diagnostic criteria, interventions, outcomes measured, potential biases per study design, control for confounding, magnitude of effect, consistency with other studies, directness of evidence, precision of estimates, and possible publication bias. For randomized controlled trials, we focused on methods used for randomization sequence generation; the allocation concealment; the level of blinding (clinician, subject, and outcome evaluator) [31]; participant flow [32]; whether an intention-to-treat analysis was used; and whether the number of cases lost to follow-up was accounted for in the trial. For allocation concealment, the following was used to grade the trials: A (appropriate i.e., central randomisation, using random number table, opaque sealed envelopes, or other described method indicating the adequacy of concealment process); B (unclear i.e., insufficient information to determine adequacy of the concealment process); $\mathrm{C}$ (inappropriate i.e., no allocation concealment was applied or if one was applied, it was deemed to be inadequate). Assessment of the quality of evidence was made independently by two authors using the GRADEprofiler software (Version 3.2 for Windows) based on the Grading of Recommendations Assessment, Development and Evaluation (GRADE) system [33]. Quality of evidence was assessed as high, moderate, low or very low. Due to the limited number of RCTs available, data from a before-and-after study is presented for completeness and to enable comparison with the concurrent, controlled studies.

\section{Results}

A total of 1,103 unique citations were identified using key words HIV or AIDS, pneumonia, and children through the initial, 
Figure 1. Search results

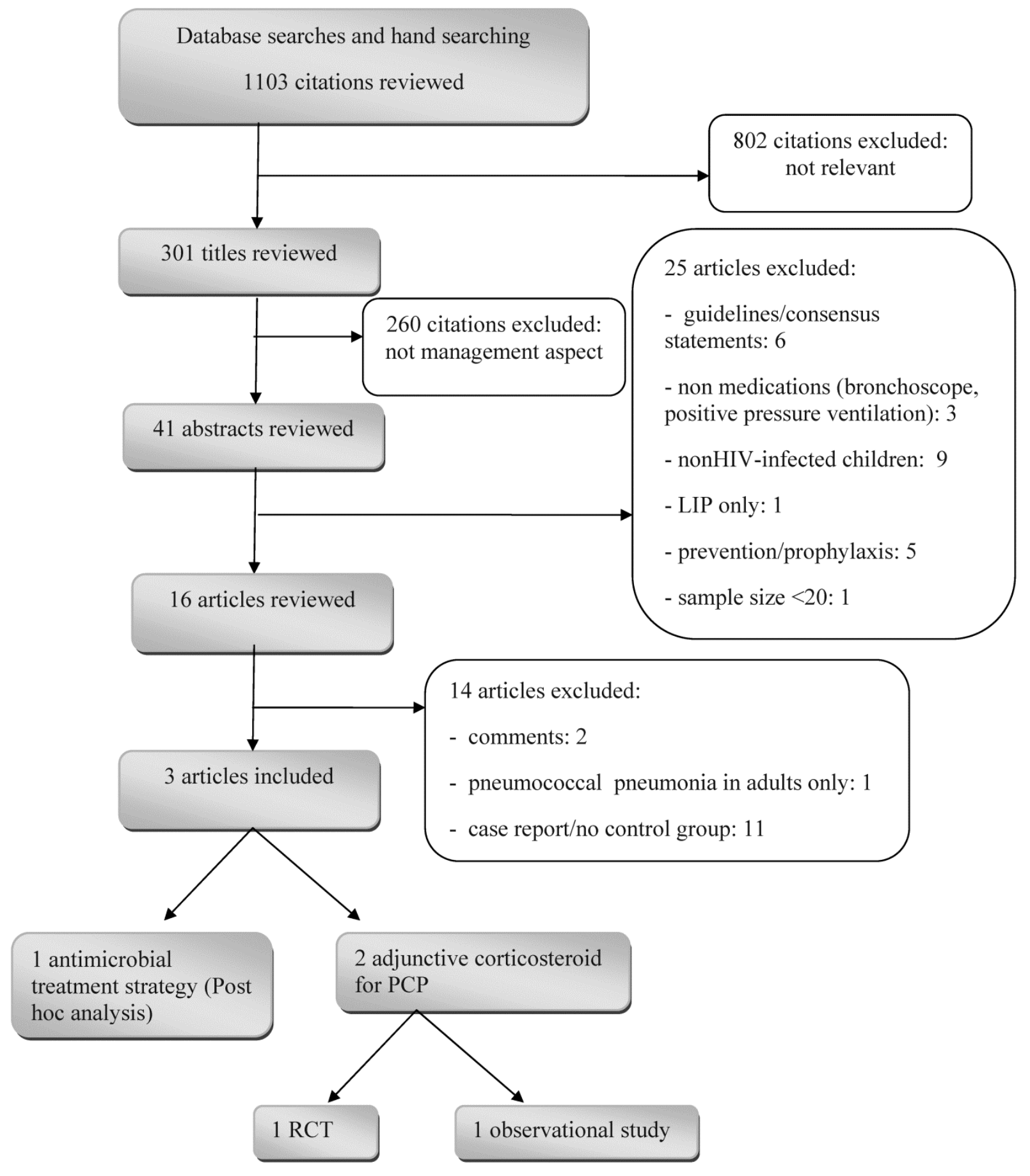


Table 3. Characteristics of a randomized control trial examining the effectiveness of adjunctive corticosteroid therapy for $P$. jirovecii pneumonia by Terblanche AJ 2008 [48]

\begin{tabular}{|l|l|}
\hline Methodology & $\begin{array}{l}\text { A random number generator was used to determine the allocation sequence. No information regarding the method of } \\
\text { allocation concealment used. Intention to treat analysis was employed. No exclusion of subjects from the final analysis. }\end{array}$ \\
\hline Participants & HIV-exposed infants with clinical diagnosis of PCP. HIV status and PCP infection were not confirmed for all participants. \\
\hline Interventions & Prednisone $2 \mathrm{mg} / \mathrm{kg} /$ day or placebo for 7 days. \\
\hline Outcomes & \begin{tabular}{l} 
The primary study endpoint: in-hospital survival. Secondary outcome: time to recovery or oxygen independency. \\
\hline Notes
\end{tabular} \\
\hline & $\begin{array}{l}\text { The study was conducted during the period when antiretroviral therapy was unavailable. The survival among the treatment } \\
\text { group appeared to be higher but it did not reach a statistically significant level. There is no information to determine } \\
\text { whether the study was adequately powered. }\end{array}$ \\
\hline
\end{tabular}

Table 4. Characteristics of a randomized control trial risk of bias: Terblanche AJ 2008 [48]

\begin{tabular}{|c|c|c|}
\hline Item & Judgment & Description \\
\hline Adequate sequence generation? & $\bigcirc$ & $\begin{array}{l}\text { A random number generator was used to determine the allocation to } \\
\text { steroid or placebo treatments, which were provided in a double-blind } \\
\text { fashion by the hospital pharmacists according to study number. }\end{array}$ \\
\hline Allocation concealment? & Unclear $\bigcirc$ & Insufficient information to determine a judgment \\
\hline Blinding? & $\bigcirc$ & \\
\hline Free of selective reporting? & $\bigcirc$ & \\
\hline Free of other bias? & No & $\begin{array}{l}\text { Biases were likely given the use of clinical diagnosis of PCP rather than } \\
\text { microbiologically proven method and the lack of PCR confirmation for } \\
\text { HIV-exposed infants. Given the relatively small sample size, } \\
\text { randomization may not successfully result in the comparable distribution } \\
\text { of outcome predictors, e.g., proportion of those truly HIV and PCP } \\
\text { infected among the two groups. Neither were the data sufficient to estimate } \\
\text { the magnitude and the overall direction of bias these potential } \\
\text { misclassifications could introduce, nor did the study design permit us to } \\
\text { adjust for potential confounders statistically. GRADE = low }\end{array}$ \\
\hline
\end{tabular}

broad bibliographical searches. Of these, 301 were deemed to be relevant by title. After manually checking the titles and abstracts, we identified 41 potentially eligible articles. However, only three articles fulfilled the criteria for inclusion: one for antimicrobial treatment and two for adjunctive corticosteroid therapy for PCP (Figure 1). Notwithstanding, no a priori planned RCT or observational studies examining either the efficacy/effectiveness of different antibiotic regimens including class of antibiotics, antibiotic dosing or duration of therapy and/or other case management strategy of pneumonia among HIV-infected or HIVexposed uninfected children were identified.

Only one subgroup analysis [30] of an RCT comparing oral amoxicillin versus parenteral penicillin for severe pneumonia in children [34] was included in our review. This selection of HIV-infected children in this substudy was also biased toward children who were either asymptomatic or only mildly symptomatic for AIDS. The results of this RCT indicated that HIVinfected children had significantly higher treatment failure rates compared to HIV-uninfected children with the risk ratios of 2.07 ; $(95 \%$ CI $1.07-4.00)$ at 48 hours and 1.88; (95\% CI 1.11- 1.37) at day 14 following randomization to study-drug [30]. The response rates were comparable between the two antibiotic regimens among both HIV-infected and uninfected children [35]. HIV-infected infants (younger than 12 months of age), however, had a significantly higher treatment failure rate at day 14 (40.7\% vs. $24.3 \%$; OR $2.8 ; 95 \%$ CI 1.35 to 3.5$)$ 
Table 5. Characteristics of an observational study examining the effectiveness of adjunctive corticosteroid therapy for $P$. jirovecii pneumonia by Bye MR 1994 [49]

\begin{tabular}{|l|l|}
\hline Methodology & A before-and-after comparison was conducted in a tertiary care setting. \\
\hline Participants & $\begin{array}{l}\text { Children with documented HIV and PCP from December 1990-1993 were compared with those from August } \\
1985-\text { Novermber 1990; both periods before the highly active antiretroviral therapy (HAART) era. }\end{array}$ \\
\hline Interventions & $\begin{array}{l}1 \mathrm{mg} / \mathrm{kg} / \text { dose of predisone or methyprednisolone sodium succinate twice a day for } 5 \mathrm{days,} \mathrm{then} 0.5 \mathrm{mg} / \mathrm{kg} \text { per } \\
\text { dose twice a day for 5 days }\end{array}$ \\
\hline Outcomes & $\begin{array}{l}\text { The primary study endpoint: death during the period of acute infection (with no information regarding the } \\
\text { length of follow-up period). Secondary outcome: requirement of mechanical ventilation. }\end{array}$ \\
\hline Notes & $\begin{array}{l}\text { The duration of recruitment of the intervention group included the transition period when the PCP prophylaxis } \\
\text { for HIV-exposed infant was initially being recommended in } 1991 \text { [42,50]. However, there was no information } \\
\text { regarding the proportion of children receiving PCP prophylaxis among the treatment group. The case fatality } \\
\text { rates among the treatment and control group were } 0 \% \text { and } 30 \%, \text { respectively. }\end{array}$ \\
\hline
\end{tabular}

Table 6. Characteristics of an observational study's risk of bias: Bye MR 1994 [49]

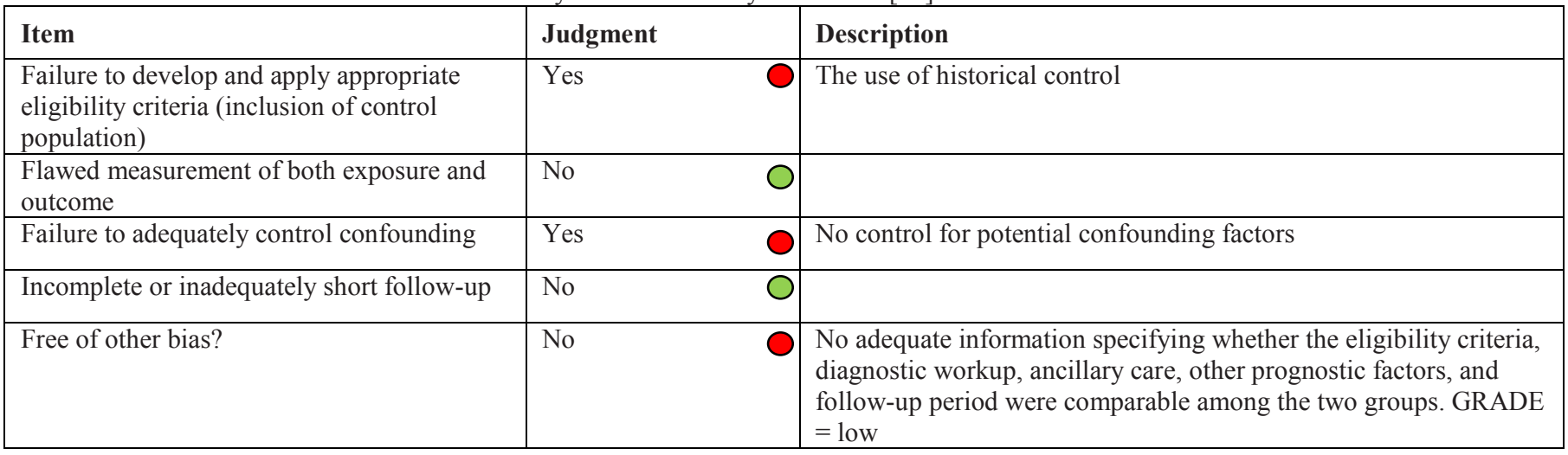

compared to HIV-uninfected infants [36]. On the other hand, response rates to the studied antibiotic regimens were similar in children older than 12 months of age, irrespective of HIV infection status. Additionally, HIV-infected children with "other type" of infiltration on chest radiograph, i.e., infiltrate not consistent with that of "alveolar consolidation" (which has been developed as a benchmark to allow for comparison of results of studies evaluating pneumococcal conjugate vaccines rather than a tool for diagnosing any form of pneumonia) [37], had higher rate of treatment failure (OR 5.45; 95\% CI 1.58 to 21.38). Details of the study characteristics and risk of bias based on the GRADE guideline are shown in Tables 1 and 2, respectively.

Apart from the subgroup analysis detailed earlier, the majority of clinical trials addressing antimicrobial therapy identified by our search mainly focused on the efficacy of the alternative treatment regimen for PCP, e.g., atovaquone suspension [38], the combination of clindamycin/primaquine [39], trimetrexate/leucovorin [40], and co-trimoxazole/folinic acid [41]. These studies were conducted in adolescent and adult populations. As the focus of this review is to develop guidelines for the empirical antimicrobial management of CAP in resource poor settings, the efficacy and effectiveness of alternate agents to co-trimoxazole for the management of CAP in HIV-infected children was not further analysed. Further, we were not able to identify any ongoing trials from a clinical trial registry (ClnicalTrials.gov).

Two studies examining the efficacy of corticosteroid treatment as an adjunctive therapy for clinical PCP in HIV-infected children satisfied the selection criteria. One was an RCT; the other was an observational study with a before-and-after comparison. Study characteristics and risk of bias of these two studies are shown in Tables 3-6.

Meta-analysis was performed for neither the antimicrobial treatment nor the adjunctive corticosteroid therapy as either only one RCT or one RCT and one observational study were identified for these interventions, respectively. In addition, pooled analysis for the adjunctive corticosteroid therapy was not deemed to be appropriate given substantial clinical and statistical heterogeneity of the studies identified. A summary of the findings for the use of adjunctive corticosteroid for Pneumocystis jirovecii pneumonia in HIV-infected children is shown in Table 7. Table 8 illustrates the quality of evidence and comparative risk of adjunctive corticosteroid treatment for Pneumocystis jirovecii pneumonia in HIV-infected children by type of outcomes using GRADEprofiler software. 
Table 7. Summary of findings table for the use of adjunctive corticosteroid for Pneumocystis jirovecii pneumonia in HIV-infected children

Question: Should adjunctive corticosteroid be used for Pneumocystis jirovecii pneumonia in HIV-infected children?

Settings: inpatients

Bibliography: Terblanche AJ, 2008

\begin{tabular}{|c|c|c|c|c|c|c|c|c|c|c|c|c|}
\hline \multirow{2}{*}{\multicolumn{7}{|c|}{ Quality assessment }} & \multicolumn{5}{|c|}{ Summary of findings } & \multirow[t]{3}{*}{ Importance } \\
\hline & & & & & & & \multicolumn{2}{|c|}{ No of patients } & \multicolumn{2}{|l|}{ Effect } & \multirow[t]{2}{*}{ Quality } & \\
\hline $\begin{array}{l}\text { No of } \\
\text { studies }\end{array}$ & Design & Limitations & Inconsistency & Indirectness & Imprecision & $\begin{array}{l}\text { Other } \\
\text { considerations }\end{array}$ & $\begin{array}{l}\text { Adjunctive } \\
\text { corticosteroid }\end{array}$ & Control & $\begin{array}{l}\text { Relative } \\
(95 \% \\
\text { CI) }\end{array}$ & Absolute & & \\
\hline \multicolumn{13}{|c|}{ Mortality rate (follow-up 0-70 days) } \\
\hline \multirow[t]{3}{*}{1} & \multirow[t]{3}{*}{$\begin{array}{l}\text { randomised } \\
\text { trial }\end{array}$} & \multirow[t]{3}{*}{ serious $^{1}$} & \multirow[t]{3}{*}{$\begin{array}{l}\text { no serious } \\
\text { inconsistency }\end{array}$} & \multirow[t]{3}{*}{$\begin{array}{l}\text { no serious } \\
\text { indirectness }\end{array}$} & \multirow[t]{3}{*}{ Serious $^{2}$} & \multirow[t]{3}{*}{ none } & \multirow[t]{3}{*}{$18 / 47(38.3 \%)$} & $27.5 \%$ & \multirow{3}{*}{$\begin{array}{l}\mathrm{RR} \\
0.812 \\
(0.512 \\
\text { to } \\
1.288)\end{array}$} & $\begin{array}{l}51 \text { fewer } \\
\text { per } 1,000\end{array}$ & \multirow[t]{3}{*}{$\begin{array}{l}\oplus \oplus \mathrm{OO} \\
\mathrm{LOW}^{1,2}\end{array}$} & \multirow[t]{3}{*}{ CRITICAL } \\
\hline & & & & & & & & $44 \%$ & & $\begin{array}{l}82 \text { fewer } \\
\text { per } 1,000\end{array}$ & & \\
\hline & & & & & & & & $52 \%^{3}$ & & $\begin{array}{l}97 \text { fewer } \\
\text { per } 1,000\end{array}$ & & \\
\hline \multicolumn{13}{|c|}{ Treatment failure at 48 hours } \\
\hline 0 & $\begin{array}{l}\text { no } \\
\text { evidence } \\
\text { available }\end{array}$ & & & & & none & & & & & & CRITICAL \\
\hline \multicolumn{13}{|c|}{ Treatment failure at day 14} \\
\hline 0 & $\begin{array}{l}\text { no } \\
\text { evidence } \\
\text { available }\end{array}$ & & & & & none & & & & & & CRITICAL \\
\hline
\end{tabular}

${ }^{1}$ The use of only unvalidated clinical diagnosis of HIV and PCP infection (no microbiologically-confirmed diagnosis of both HIV and Pneumocystis jirovecii pneumonia)

${ }^{2}$ Sample size was less than 300 without precalculation for optimal sample size and thus no information regarding adequacy of study power.

${ }^{3}$ The baseline risks are obtained from 7 published observational studies including: Ruffini DD, AIDS. 2002 Jan 4;16(1):105-12; Madhi SA, Clin Infect Dis. 2002 Nov 1;35(9):1120-6; Marolda J Pediatr Pulmonol. 1989;7(4):230-4. Graham SM. Lancet. 2000 Jan 29;355(9201):369-73; Bakeera-Kitaka S. Ann Trop Paediatr. 2004 Sep;24(3):227-35; Zar HJ. Pediatr Infect Dis J. 2000 Jul;19(7):603-7; Bye MR. Pediatr Pulmonol. 1990;9(4):251-3. For a high- and low-risk population we chose the second highest and second lowest control group risks in the included studies. 


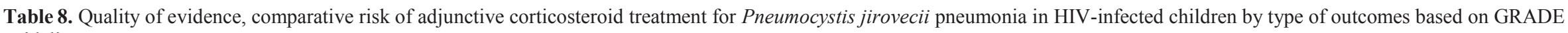
guideline

Adjunctive corticosteroid for Pneumocystis jirovecii pneumonia in HIV-infected children

Patient or population: patients with Pneumocystis jirovecii pneumonia in HIV-infected children

Settings: inpatients

Intervention: adjunctive corticosteroid

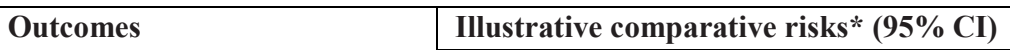

\begin{tabular}{|c|c|c|}
\hline & \multicolumn{2}{|c|}{ (2) } \\
\hline & Assumed risk & Corresponding risk \\
\hline & Control & adjunctive corticosteroid \\
\hline
\end{tabular}

Mortality rate

Low risk population ${ }^{3}$

(follow-up: 0-70 days)

275 per 1,000

223 per 1,000

(141 to 354 )

Medium risk population

\begin{tabular}{|l|l}
\hline 440 per 1,000 & 357 per 1,000
\end{tabular}

(225 to 567)

\begin{tabular}{|l|l|} 
& \multicolumn{1}{|c}{$(225$ to 567$)$} \\
\cline { 2 - 3 } & High risk population $^{3}$
\end{tabular}

\begin{tabular}{|l|l|l|}
\hline & $\mathbf{5 2 0}$ per $\mathbf{1 , 0 0 0}$ & $\begin{array}{l}\mathbf{4 2 2} \text { per } \mathbf{1 , 0 0 0} \\
(266 \text { to } 670)\end{array}$ \\
\hline Treatment failure at $\mathbf{4 8}$ hours & Not estimable & Not estimable \\
\hline
\end{tabular}

Treatment failure at day 14

Not estimable

Not estimable

\begin{tabular}{|c|c|c|c|}
\hline $\begin{array}{l}\text { Relative effect } \\
(95 \% \mathrm{CI})\end{array}$ & $\begin{array}{l}\text { No of Participants } \\
\text { (studies) }\end{array}$ & $\begin{array}{l}\text { Quality of the evidence } \\
\text { (GRADE) }\end{array}$ & Comments \\
\hline $\begin{array}{l}\text { RR 0.812 } \\
(0.512 \text { to } 1.288)\end{array}$ & $\begin{array}{l}100 \\
(1)\end{array}$ & $\begin{array}{l}\oplus \oplus \mathrm{OO} \\
\text { low }\end{array}$ & \\
\hline Not estimable & - & Not estimable & \\
\hline Not estimable & - & Not estimable & \\
\hline
\end{tabular}

*The basis for the assumed risk (e.g., the median control group risk across studies) is provided in footnotes. The corresponding risk (and its $95 \%$ confidence interval) is based on the

assumed risk in the comparison group and the relative effect of the intervention (and its $95 \% \mathrm{CI}$ ).

CI: Confidence interval; RR: Risk ratio;

GRADE Working Group grades of evidence

High quality: Further research is very unlikely to change our confidence in the estimate of effect.

Moderate quality: Further research is likely to have an important impact on our confidence in the estimate of effect and may change the estimate.

Low quality: Further research is very likely to have an important impact on our confidence in the estimate of effect and is likely to change the estimate.

Very low quality: We are very uncertain about the estimate.

${ }^{1}$ The use of only unvalidated clinical diagnosis of HIV and PCP infection (no microbiologically-confirmed diagnosis of both HIV and Pneumocystis jirovecii pneumonia)

${ }^{2}$ Sample size was less than 300 without precalculation for optimal sample size and thus no information regarding adequacy of study power.

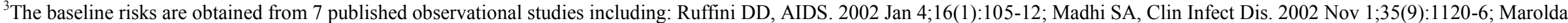

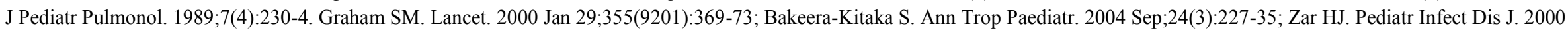

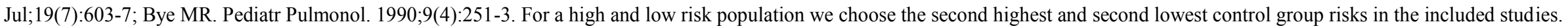

* GRADE: Grading of Recommendations Assessment, Development and Evaluation 


\section{Discussion}

Our findings are limited by the paucity of RCTs available. A single RCT illustrated a non-significant advantage against mortality in HIV-exposed children with clinical suspicion of PCP, while the observation study in the United States indicated a significant reduction in PCP case fatality rates. This finding is consistent with existing literature which indicates that observational studies using historical controls may overestimate interventions [42]. The observational study on adjunctive steroid therapy was also unclear on whether all cases in the control group underwent invasive diagnostic procedure and attained microbiologically proven diagnosis as was done in the intervention group. Additionally, no information was provided on CPT among the children who developed PCP, which was first recommended in early 1991[43], i.e., prior to when the historical control group were identified and during the period when the intervention group were recruited. This would be important as a history of CPT was found to be associated with substantial reduction in mortality risk among HIVinfected children with CAP in whom $P$. jirovecii was identified [15]. Despite the strong association (RR > 5 ), the lack of control for potential confounding factors and possibility of publication bias due to favourable results render this study low quality as scientific evidence.

Additionally, neither study was specifically designed to systematically evaluate the potential for steroid therapy to be associated with adverse events, particularly the effect of possible re-activation of latent $\mathrm{CMV}$ infection. Although adjunctive steroid therapy has been shown to be beneficial in the management of PCP in HIV-infected adults in industrialized country settings [44], its extrapolation to $\mathrm{HIV}$-infected infants has limitations. Reasons include the likely differences in the pathogenesis of PCP in young infants; i.e., it is most likely related to progression of primary Pneumocystis jirovecii infection in a naive host, instead of re-infection or reactivation as would occur in severely immunocompromised HIV-infected adults. Additionally, the potential for high-dose steroid therapy to interfere with the control of co-existing CMV infection may be greater in HIV-infected infants in Africa compared to HIV-infected adults in industrialized settings. Coupled with the absence of safety data in populations most affected by HIV/AIDS the results in this review do not support the empirical use of adjunctive steroid treatment in HIV-infected children with suspected or proven PCP.
No a priori planned clinical trials against CAP in HIV-affected children which examined different antibiotic regimens including antibiotic drug class, antibiotic doses, or antibiotic duration of therapy were identified through the systematic review. This is despite the fact that HIV-infected children account for as much as $45 \%$ of all CAP hospitalizations [7] in some sub-Saharan African countries which contributes to a disproportionately high burden of the global childhood pneumonia mortality. The high failure rate of the WHO-recommended antibiotic regimens for management of severe pneumonia in HIV-infected children [30], coupled with the greater diversity of pathogens and differences in antibiotic susceptibility patterns of bacteria causing CAP, as well as the greater frequency of polymicrobial pathogens in HIV-infected compared to HIV-uninfected children with CAP, dictates that there is an urgent need to reconsider the recommended empiric management of CAP in countries with a high prevalence of HIV infection. This appears to be particularly pertinent in infants, among whom the burden of CAP is greatest [2] and in whom there is a high incidence of PCP, polymicrobial infection, and infection caused by resistant pathogens $[7,35]$. There is an urgent need to conduct RCT comparative studies on different anti-bacterial and/or anti-viral agents in HIV-infected children.

\section{Conclusion}

This systematic review has identified the need for well-designed, adequately powered randomized controlled trials to assess different antibiotic regimens which are better tailored toward adequately targeting pathogens commonly implicated in the aetiology of pneumonia in HIV-infected as well as possibly HIVexposed uninfected children. The variable availability of antiretroviral treatment, CPT as well as conjugate bacterial vaccines targeting $H$. influenzae type $\mathrm{b}$ and selected pneumococcal serotypes, however, is likely to be a major factor in the design of studies evaluating optimal antibiotic regimens in HIV-infected children. Studies are also required to specifically address issues related to the management of CAP in HIV-exposed uninfected children, among whom there have been case series reports of heightened susceptibility to pathogens not commonly identified in immunocompetent HIV-unexposed uninfected children [14,35] 


\section{Acknowledgements}

The authors thank members of the WHO Guideline Development Group on Management of Pneumonia and Diarrhoea in HIVinfected infants and children for their participation in the review of the meta-analysis and efforts at revising the guidelines for the management of pneumonia in HIV-infected children.

\section{References}

1. Bryce J, Boschi-Pinto C, Shibuya K, Black RE (2005) WHO estimates of the causes of death in children. Lancet 365 : 1147-1152.

2. Rudan I, Boschi-Pinto C, Biloglav Z, Mulholland K, Campbell H (2008) Epidemiology and etiology of childhood pneumonia. Bull World Health Organ 86: 408-416.

3. Bradshaw D, Groenewald P, Laubscher R, Nannan N, Nojilana B, Norman R, Pieterse D, Schneider M, Bourne DE, Timaeus IM, Dorrington R, Johnson L (2003) Initial burden of disease estimates for South Africa, 2000. S Afr Med J 93: 682-688

4. Haddad A (2008) Children's access to HIV drugs increases in sub-Saharan Africa, but still is not enough. Available: http://www.mediaglobal.org/article/2008-06-10/childrensaccess-to-hiv-drugs-increases-in-sub-saharan-africa-but-stillis-not-enough. Accessed 24 April 2009.

5. The Pneumococcal vaccines Accelerated Development and Introduction Plan. Vaccine Introduction. Available: http://www.pneumoadip.org/vaccine/. Accessed 23 April 2009.

6. Zar HJ (2008) Chronic lung disease in human immunodeficiency virus (HIV) infected children. Pediatr Pulmonol 43: 1-10.

7. Madhi SA, Petersen K, Madhi A, Khoosal M, Klugman KP (2000) Increased disease burden and antibiotic resistance of bacteria causing severe community-acquired lower respiratory tract infections in human immunodeficiency virus type 1infected children. Clin Infect Dis 31: 170-76.

8. Zar HJ, Hanslo D, Tannenbaum E, Klein M, Argent A, Eley B, Burgess J, Magnus K, Bateman ED, Hussey G (2001) Aetiology and outcome of pneumonia in human immunodeficiency virus-infected children hospitalized in South Africa. Acta Paediatr 90: 119-125.

9. Marolda J, Pace B, Bonforte RJ, Kotin N, Kattan M (1989) Outcome of mechanical ventilation in children with acquired immunodeficiency syndrome. Pediatr Pulmonol 7: 230-234.

10. Graham SM, Mtitimila EI, Kamanga HS, Walsh AL, Hart CA, Molyneux ME (2000) Clinical presentation and outcome of Pneumocystis carinii pneumonia in Malawian children. Lancet 355: 369-373.

11. Bakeera-Kitaka S, Musoke P, Downing R, Tumwine JK (2004) Pneumocystis carinii in children with severe pneumonia at Mulago Hospital, Uganda. Ann Trop Paediatr 24: $227-235$

12. Zar HJ, Dechaboon A, Hanslo D, Apolles P, Magnus KG, Hussey G (2000) Pneumocystis carinii pneumonia in South African children infected with human immunodeficiency virus. Pediatr Infect Dis J 19: 603-607.

13. Bye MR, Bernstein LJ, Glaser J, Kleid D (1990) Pneumocystis carinii pneumonia in young children with AIDS. Pediatr Pulmonol 9: 251-253.

14. Ruffini DD, Madhi SA (2002) The high burden of Pneumocystis carinii pneumonia in African HIV-1-infected children hospitalized for severe pneumonia. AIDS 16: 105112.
15. Madhi SA, Cutland C, Ismail K, O'Reilly C, Mancha A, Klugman KP (2002) Ineffectiveness of trimethoprimsulfamethoxazole prophylaxis and the importance of bacterial and viral coinfections in African children with Pneumocystis carinii pneumonia. Clin Infect Dis 35: 1120-1126.

16. Zar HJ, Maartens G, Wood R, Hussey G (2000) Pneumocystis carinii pneumonia in HIV-infected patients in Africa--an important pathogen? S Afr Med J 90: 684-688.

17. Uriyo J, Gosling RD, Maddox V, Sam NE, Schimana W, Gillespie SH, McHugh TD (2006) Prevalences of Pneumocystis jiroveci, Mycobacterium tuberculosis and Streptococcus pneumoniae infection in children with severe pneumonia, in a tertiary referral hospital in northern Tanzania. Ann Trop Med Parasitol 100: 245-249.

18. Jeena PM, Coovadia HM, Chrystal V (1996) Pneumocystis carinii and cytomegalovirus infections in severely ill, HIVinfected African infants. Ann Trop Paediatr 16: 361-368.

19. Barnhart HX, Caldwell MB, Thomas P, Mascola L, Ortiz I, Hsu HW, Schulte J, Parrott R, Maldonado Y, Byers R (1996) Natural history of human immunodeficiency virus disease in perinatally infected children: an analysis from the Pediatric Spectrum of Disease Project. Pediatrics 97: 710-716.

20. Bii CC, Kose J, Taguchi H, Amukoye E, Ouko TT, Muita LC, Mugasia O, Wamae N, Kamiya S (2006) Pneumocystis jirovecii and microbiological findings in children with severe pneumonia in Nairobi, Kenya. Int J Tuberc Lung Dis 10: 1286-1291.

21. Blanche S, Rouzioux C, Moscato ML, Veber F, Mayaux MJ, Jacomet C, Tricoire J, Deville A, Vial M, Firtion G, et al. (1989) A prospective study of infants born to women seropositive for human immunodeficiency virus type 1. HIV Infection in Newborns French Collaborative Study Group. N Engl J Med 320: 1643-1648.

22. Gibb DM, Davison CF, Holland FJ, Walters S, Novelli V, Mok J (1994) Pneumocystis carinii pneumonia in vertically acquired HIV infection in the British Isles. Arch Dis Child 70: 241-244.

23. Williams AJ, Duong T, McNally LM, Tookey PA, Masters J, Miller R, Lyall EG, Gibb DM (2001) Pneumocystis carinii pneumonia and cytomegalovirus infection in children with vertically acquired HIV infection. AIDS15: 335-339.

24. Simonds RJ, Oxtoby MJ, Caldwell MB, Gwinn ML, Rogers MF (1993) Pneumocystis carinii pneumonia among US children with perinatally acquired HIV infection. JAMA 270: 470-473.

25. Ikeogu MO, Wolf B, Mathe S (1997) Pulmonary manifestations in HIV seropositivity and malnutrition in Zimbabwe. Arch Dis Child 76: 124-128.

26. Lucas SB, Peacock CS, Hounnou A, Brattegaard K, Koffi K, Honde M, Andoh J, Bell J, De Cock KM (1996) Disease in children infected with HIV in Abidjan, Cote d'Ivoire. BMJ 312: 335-338

27. Moran CA, Suster S, Pavlova Z, Mullick FG, Koss MN (1994) The spectrum of pathological changes in the lung in children with the acquired immunodeficiency syndrome: an autopsy study of 36 cases. Hum Pathol 25: 877-882.

28. Nathoo KJ, Gondo M, Gwanzura L, Mhlanga BR, Mavetera T, Mason PR (2001) Fatal Pneumocystis carinii pneumonia in HIV-seropositive infants in Harare, Zimbabwe. Trans R Soc Trop Med Hyg 95: 37-39.

29. Rennert WP, Kilner D, Hale M, Stevens G, Stevens W, Crewe-Brown H (2002) Tuberculosis in children dying with 
HIV-related lung disease: clinical-pathological correlations. Int J Tuberc Lung Dis 6: 806-813.

30. Jeena P, Thea DM, MacLeod WB, Chisaka N, Fox MP, Coovadia HM, Qazi S (2006) Failure of standard antimicrobial therapy in children aged 3-59 months with mild or asymptomatic HIV infection and severe pneumonia. Bull World Health Organ 84: 269-275.

31. Noseworthy JH, Ebers GC, Vandervoort MK, Farquhar RE, Yetisir E, Roberts R (1994) The impact of blinding on the results of a randomized, placebo-controlled multiple sclerosis clinical trial. Neurology 44: 16-20.

32. Egger M, Juni P, Bartlett C (2001) Value of flow diagrams in reports of randomized controlled trials. Jama 285: 1996-1999.

33. Global Programme on Evidence for Health Policy, World Health Organization (2003) Guidelines for WHO Guidelines. Available:

http://whqlibdoc.who.int/hq/2003/EIP_GPE_EQC_2003_1.pd f. Accessed 23 March 2009.

34. Addo-Yobo E, Chisaka N, Hassan M, Hibberd P, Lozano JM, Jeena P, MacLeod WB, Maulen I, Patel A, Qazi S, Thea DM, Nguyen NT (2004) Oral amoxicillin versus injectable penicillin for severe pneumonia in children aged 3 to 59 months: a randomised multicentre equivalency study. Lancet 364: 1141-1148.

35. McNally LM, Jeena PM, Gajee K, Thula SA, Sturm AW, Cassol S, Tomkins AM, Coovadia HM, Goldblatt D (2007) Effect of age, polymicrobial disease, and maternal HIV status on treatment response and cause of severe pneumonia in South African children: a prospective descriptive study. Lancet 369: 1440-1451.

36. Jeena PM, Minkara AK, Corr P, Bassa F, McNally LM, Coovadia HM, Fox M, Hamer DH, Thea D (2007) Impact of HIV-1 status on the radiological presentation and clinical outcome of children with WHO defined community-acquired severe pneumonia. Arch Dis Child 92: 976-979.

37. Cherian T, Mulholland EK, Carlin JB, Ostensen H, Amin R, de Campo M, Greenberg D, Lagos R, Lucero M, Madhi SA, O'Brien KL, Obaro S, Steinhoff MC (2005) Standardized interpretation of paediatric chest radiographs for the diagnosis of pneumonia in epidemiological studies. Bull World Health Organ 83: 353-359.

38. Rosenberg DM, McCarthy W, Slavinsky J, Chan CK, Montaner J, Braun J, Dohn MN, Caldwell PT (2001) Atovaquone suspension for treatment of Pneumocystis carinii pneumonia in HIV-infected patients. AIDS 15: 211-214.

39. Black JR, Feinberg J, Murphy RL, Fass RJ, Finkelstein D, Akil B, Safrin S, Carey JT, Stansell J, Plouffe JF, et al. (1994) Clindamycin and primaquine therapy for mild-to-moderate episodes of Pneumocystis carinii pneumonia in patients with AIDS: AIDS Clinical Trials Group 044. Clin Infect Dis 18: 905-913.

40. Sattler FR, Frame P, Davis R, Nichols L, Shelton B, Akil B, Baughman R, Hughlett C, Weiss W, Boylen CT, et al. (1994) Trimetrexate with leucovorin versus trimethoprim- sulfamethoxazole for moderate to severe episodes of Pneumocystis carinii pneumonia in patients with AIDS: a prospective, controlled multicenter investigation of the AIDS Clinical Trials Group Protocol 029/031. J Infect Dis 170: 165172.

41. Safrin S, Lee BL, Sande MA (1994) Adjunctive folinic acid with trimethoprim-sulfamethoxazole for Pneumocystis carinii pneumonia in AIDS patients is associated with an increased risk of therapeutic failure and death. J Infect Dis 170: 912917.

42. Sacks H, Chalmers TC, Smith H, Jr. (1982) Randomized versus historical controls for clinical trials. Am J Med 72: 233-240.

43. (1991) Guidelines for prophylaxis against Pneumocystis carinii pneumonia for children infected with human immunodeficiency virus. MMWR Recomm Rep 40: 1-13.

44. Briel M, Bucher HC, Boscacci R, Furrer H (2006) Adjunctive corticosteroids for Pneumocystis jiroveci pneumonia in patients with HIV infection. Cochrane Database Syst Rev 3: CD006150.

45. Guillemin F (2007) Primer: the fallacy of subgroup analysis. Nat Clin Pract Rheumatol 3: 407-413.

46. Rothwell PM (2005) Treating individuals 2. Subgroup analysis in randomised controlled trials: importance, indications, and interpretation. Lancet 365: 176-186.

47. Brookes ST, Whitely E, Egger M, Smith GD, Mulheran PA, Peters TJ (2004) Subgroup analyses in randomized trials: risks of subgroup-specific analyses; power and sample size for the interaction test. J Clin Epidemiol 57: 229-236.

48. Terblanche AJ, Green RJ, Rheeder P, Wittenberg DF (2008) Adjunctive corticosteroid treatment of clinical Pneumocystis jiroveci pneumonia in infants less than 18 months of age--a randomised controlled trial. S Afr Med J 98: 287-290.

49. Bye MR, Cairns-Bazarian AM, Ewig JM (1994) Markedly reduced mortality associated with corticosteroid therapy of Pneumocystis carinii pneumonia in children with acquired immunodeficiency syndrome. Arch Pediatr Adolesc Med 148: 638-641.

50. Kunz R and Oxman AD (1998) The unpredictability paradox: review of empirical comparisons of randomised and nonrandomised clinical trials. BMJ 317: 1185-1190.

\section{Corresponding author}

Warunee Punpanich

Department of Pediatrics

Queen Sirikit National Institute of Child Health

College of Medicine

Rangsit University

Thailand, 10400

Telephone/Fax: + 6623548345

Email:warunee@vandepitte.eu

Conflict of interests: No conflict of interests is declared. 